\title{
Comparing the Influence of Residual Stresses in Bearing Fatigue Life at Line and Point Contact
}

\author{
Timm Coors ${ }^{1,{ }^{*}}$, Florian Pape ${ }^{1}$ and Gerhard Poll ${ }^{1}$ \\ ${ }^{1}$ Institute of Machine Design and Tribology, Leibniz University Hannover, Welfengarten 1 A, \\ 30167 Hannover, Germany \\ *coors@imkt.uni-hannover.de
}

\section{Keywords: Residual Stress, Bearing Fatigue Life, Tailored Forming}

\begin{abstract}
The targeted insertion of compressive residual stresses can positively influence the fatigue life of rolling element bearings. Adapted manufacturing processes such as hard turning and deep rolling can help optimising the subsurface residual stress state of these machine elements, which also improves the surface quality of the bearings raceway. In this contribution, a numerical calculation method was developed to predict the influence of residual stresses on bearing fatigue life. By means of a finite element analysis, the component stresses due to the rolling contact load can be determined. The resulting shear stresses find input in a bearing fatigue life calculation based on the approach of IOANNIDES, BERGLING and GABELLI. This statistically based method refers a material-dependent stress fatigue limit to a local stress related fatigue criterion, which is influenced by the residual stress condition. On this basis, the influence of residual stresses on two different bearing types is investigated. Line contact is represented by a cylindrical roller bearing and an angular contact ball bearing is chosen to investigate the point contact. For angular contact ball bearings, a rolling motion is superimposed by a drilling movement perpendicular to the contact plane, which is caused by the kinematics of the rolling element. The calculation method is used for bearings made of classic bearing steel and bearings made of two different steels by tailored forming in order to regard the residual stress conditions of different manufacturing types. It can be shown that the influence of residual stresses on bearing fatigue life is higher for bearings with line contact than for bearings with point contact.
\end{abstract}

\section{Introduction}

Rolling bearings are widely used machine elements, which used in mechanical and plant engineering, drive technology or energy industry. They are used to fix shafts, transmitting forces between shaft and housing and at the same time allowing the shaft to rotate. Rolling bearings typically consist of an inner and an outer raceway, between which several rolling elements (Fig. 1: yellow) roll with low frictional losses. Rolling bearings can be differentiated according to the shape of their rolling elements in roller bearings and ball bearings, for which the contact area between rolling element and raceway is different. In the case of roller bearings (Fig. 1a), the contact is in the form of a line under conditions of zero load. With ball bearings (Fig. 1b), the contact area can be idealized by a point contact. Due to the elastic material behavior under the influence of an external force $F$, elastic deformation occurs in the contact. The idealized contacts then form two-dimensional surfaces. Previous studies showed a positive influence of pre-induced residual stresses by manufacturing related boundary zone properties [2] or the targeted use of high-strength materials [3] on bearing fatigue life, which therefore has to be regarded at rolling contact fatigue conditions [4][5][6]. In the presented paper, the following rolling bearings are considered exemplarily to compare the influence of residual stresses in bearing fatigue life at line and point contact in order to calculate the load-bearing capacity and the fatigue life under cyclic rolling loads: 
a)

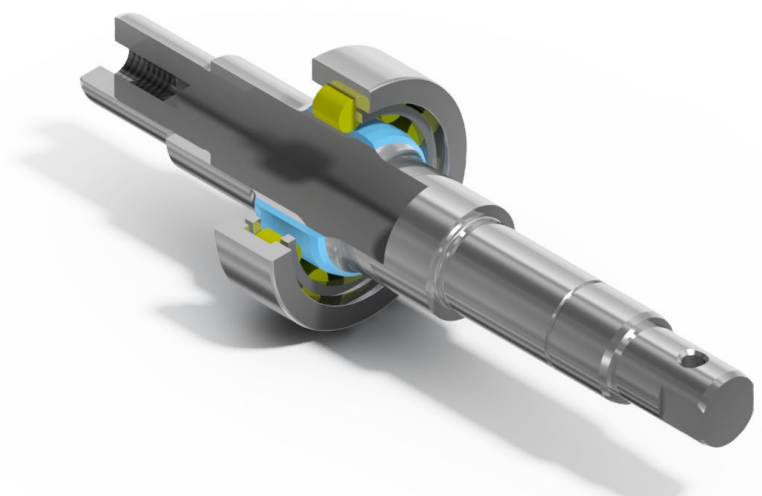

b)

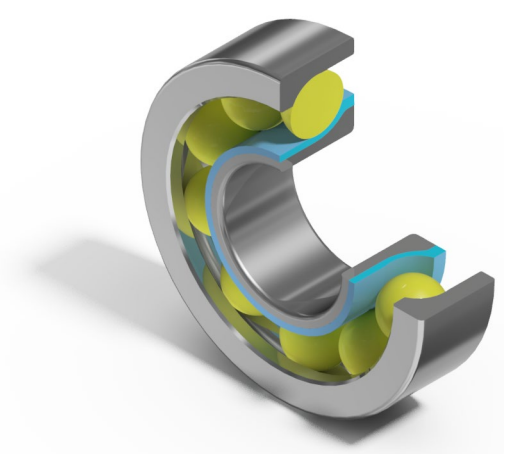

Fig. 1: Contact conditions for two exemplary Tailored Forming demonstrator components: a) cylindrical roller bearing with line contact; b) angular contact ball bearing with point contact.

A cylindrical roller bearing type RNU 204 represents a line contact. The inner ring was substituted by a shaft (Fig. 1a), which in turn was designed and manufactured within the Collaborative Research Centre 1153 “Tailored Forming“. In this process chain, a hybrid semifinished product is produced from two different steel alloys by cladding through plasma transferred arc welding and then formed subsequently by cross-wedge rolling [7]. This offers material and process-related advantages, because a high strength steel (material number 1.7035) can be bonded to an inexpensive steel (1.0402). The cladding steel is commonly considered to be poorly weldable, but offers a good hardness and fatigue resistance [8].

The angular contact ball bearing type 7306 shown in Fig. 1b) is also cladded with a high performance material on which the rolling elements run. This second tailored forming part is used to represent a highly loaded point contact.

\section{Method of calculation}

The functional capability and fatigue life of a rolling bearing are primarily determined by the boundary zone properties of the finished component, as they are directly exposed to mechanical loads. In order to calculate the stress state under load, a finite elements (FE) model was set up for each component using Ansys Mechanical APDL (see Fig. 2a and b). For the fatigue life calculation described below, only the most heavily loaded material volume is assumed to be critical for damage. Focus has therefore been set on the inner raceway and the symmetry of geometry was used by modeling a $9^{\circ}$-segment of each component. The contact area is discretised with a regularly mapped fine mesh. The remaining supporting structure is meshed with tetrahedron-shaped elements (see Fig. 2). As input parameters, local material properties of both, the high strength cladding and the base material, as well as the geometry of the contact zone (rolling element profiling) are taken into account. According to the HERTzian contact theory [9], the external load is transformed into a three-dimensional pressure distribution, which is then applied as initial stress to the inner rings surface. For angular contact ball bearings (Fig. 2b) the rolling motion is superimposed by a drilling movement perpendicular to the contact plane, whereby sliding friction occurs in the contacting area [10].

Pre-induced residual stresses, which may result from the manufacturing process, e.g. tempering, hard turning or deep rolling, are also applied as initial stress state regarding the residual stress depth profile in circumferential direction. The subsurface residual stress state was measured based on experimental x-ray diffractometry. In this work, a residual stress state induced by deep rolling is applied to the model (cf. Fig. 2). Due to deep rolling, residual stresses of up to -1000 $\mathrm{MPa}$ with a maximum depth of $100 \mu \mathrm{m}$ could be achieved in previous measurements on cylindrical roller bearings [11]. 


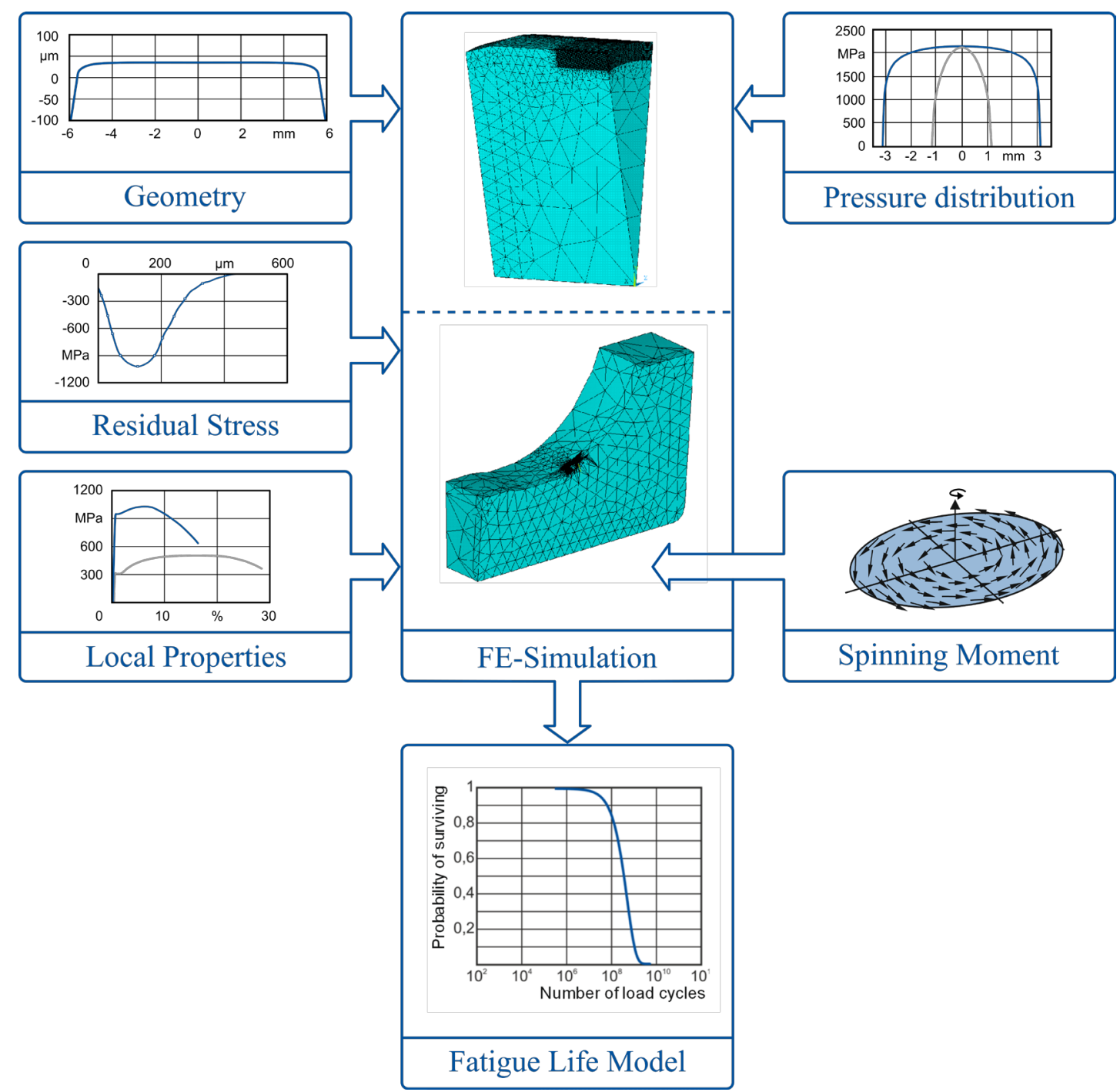

Fig. 2: Flow chart of fatigue life calculation: a) line contact; b) point contact.

Solving the FE simulation provides the 3D shear stresses and hydrostatic stresses in the inner rings resulting from the superimposition of the loading pressure distribution and the residual stress state. Peak value and location of this stress field are used to calculate the bearing fatigue life in Mathworks Matlab for the parts volume under the influence of rolling contact fatigue based on the approach of IoANNiDES, BERGLING and GabelLi [12][13]. This statistically based method refers a material-dependent stress fatigue limit to a local stress related fatigue criterion, which is again influenced by the residual stress condition. Here, the DANG VAN stress criterion is used, which sets the orthogonal shear stress in relation to the hydrostatic stress [14]. To cause a damage a limiting value resulting from a linear combination of both conditions has to be exceeded.

\section{Computation results}

Based on the calculation approach described above, the FE model was first solved to analyse the component stress state for the examples of lines and point contact. For comparability, a resulting HERTZian pressure of about 2.1 GPa for each component was applied. This represents a medium to high load on the rolling bearing, which are used in fatigue tests [15]. The input parameters for the simulation can be found in Table 1 and Fig. 2. The height of the cladding layer was $0.5 \mathrm{~mm}$, which only has a slight effect on the fatigue life [16]. 
Table 1: Input parameters

\begin{tabular}{|l|l|l|}
\hline Material number & Young's modulus E (GPa) & $\begin{array}{l}\text { Assumed shear stress } \\
\text { fatigue limit } \tau_{\mathrm{u}}(\mathrm{MPa})\end{array}$ \\
\hline 1.7035 & 210 & 300 \\
\hline 1.0402 & 209 & 210 \\
\hline
\end{tabular}

Fig. 3 shows the equivalent stresses according to the VON MISES yield criterion without consideration of residual stresses. It is obvious that the maximum stresses in the material should occur within the higher strength part volume in order to prevent fatigue damage in the base material. According to the HERTzian theory, the line contact (Fig. 3a) loads a larger component volume with the same maximum pressure as the point contact (Fig. 3b).

a)

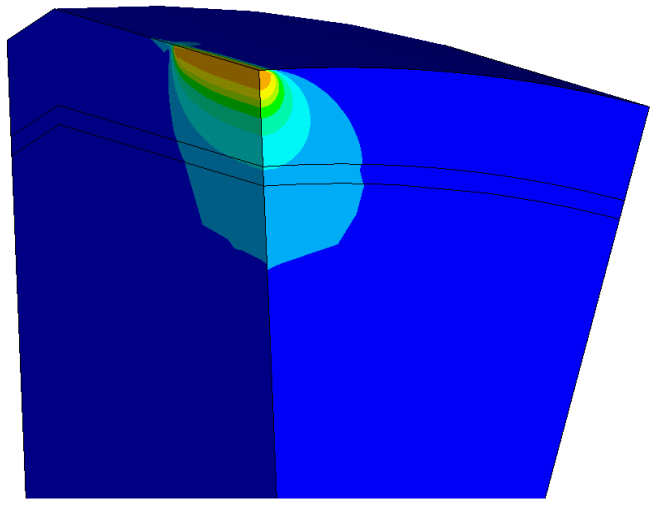

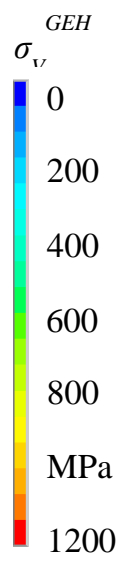

b)

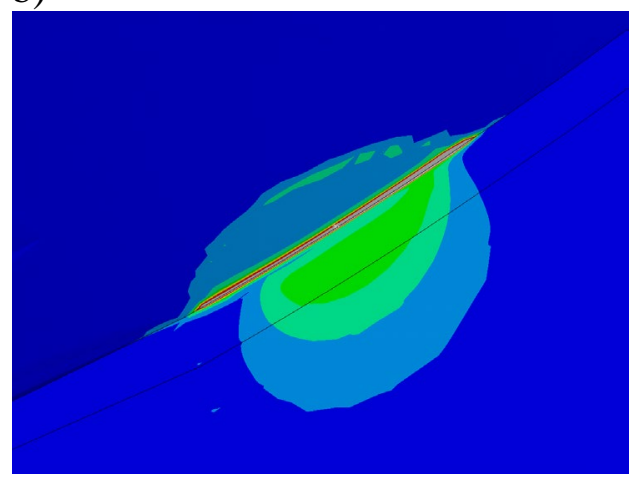

Fig. 3: Induced VON MISES stresses at a HERTZian pressure of 2.1 GPa without consideration of residual stresses: a) line contact; b) point contact.

The critical fatigue stress is highest in the component volume of the highest load-induced stress below the surface. By applying compressive residual stresses at this depth, the damage relevant stresses are reduced (cf. Fig. 4) and bearing life can be positively influenced. With preinduced residual stresses, the maximum stress is also shifted towards the surface so that a thinner cladding thickness is sufficient.

a)

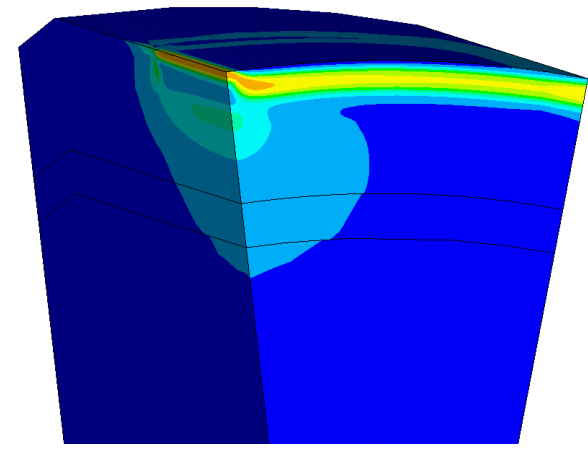

$\sigma_{\mathrm{v}}^{G E H}$
200
400
600
800
$\mathrm{MPa}$
1200

b)

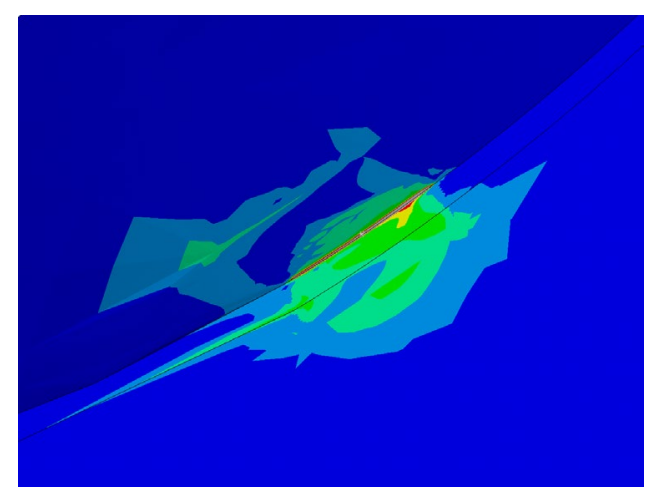

Fig. 4: Induced VON MISES stresses at a HERTZian pressure of 2 GPa with residual stress depth profile through deep rolling (see Fig. 2): a) line contact; b) point contact.

Fig. 5 depicts the calculated bearing fatigue life for the exemplary bearings with line and point contact. To verify the approach, fatigue tests were carried out on a test bench with specimen made form monolithic high strength steel. The calculation and bench tests show good agreement. 
It becomes clear, that a pre-induced residual stress state affects the fatigue life positively by a factor of 1.6 (line contact) respectively 1.3 (point contact). The influence is higher for line contacts, because the damage-critical volume is larger, which increases the cumulated probability of fatigue damage. Note that the higher fatigue life of the angular contact ball bearing results from lower overall external load on the bearing, which is sufficient for the selected surface pressure.

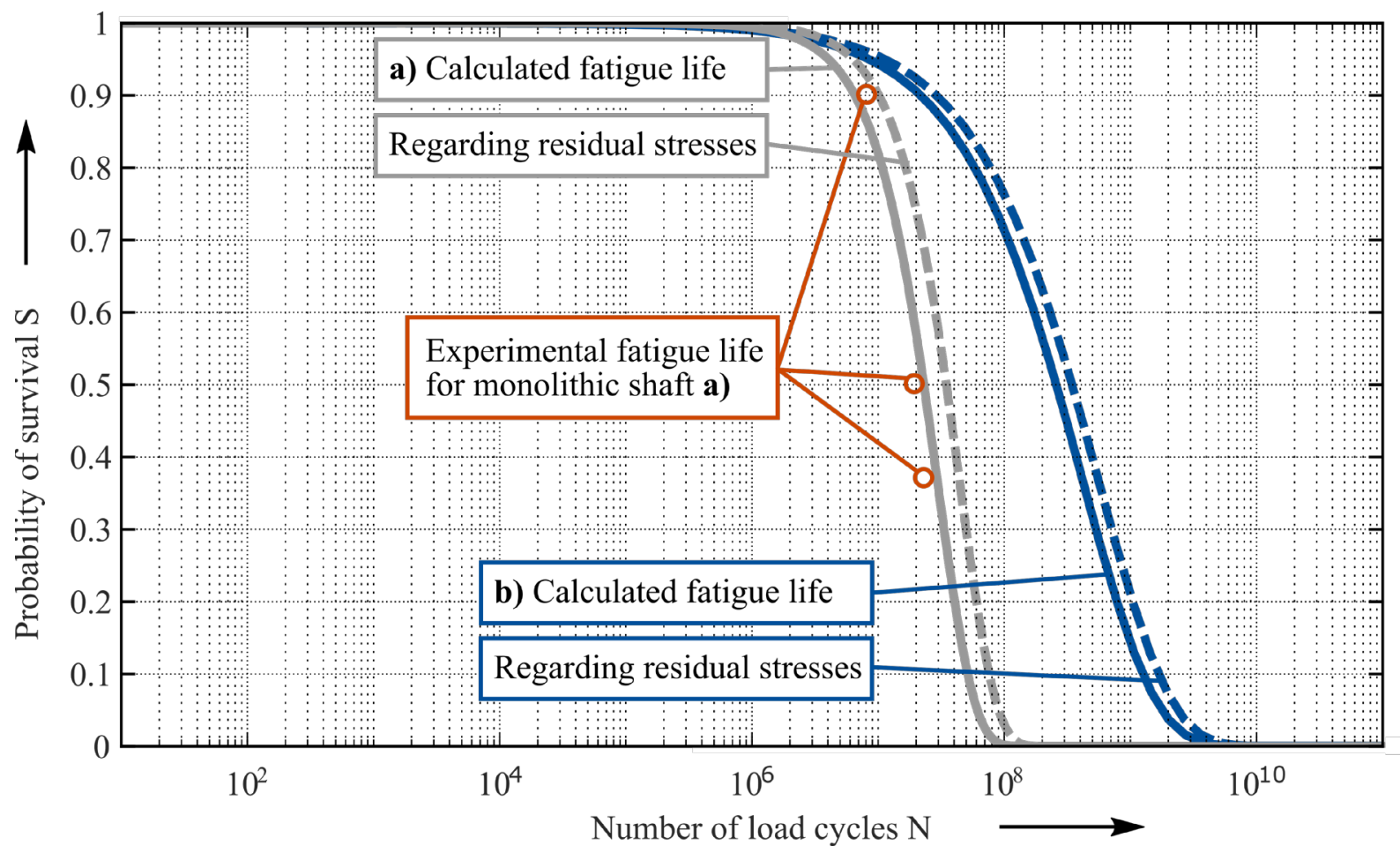

Fig. 5: Comparing the influence of residual stresses in bearing fatigue life for specimen with a HERTZian contact pressure of $2 \mathrm{GPa}$ : $a$ ) line contact and $b$ ) point contact.

\section{Summary}

This paper presents the difference between line and point contact regarding bearing fatigue life, in case of pre-induced residual stresses. It can be shown that the influence of residual stresses on bearing fatigue life is considerably greater for bearings with line contact than for bearings with point contact. This is due to the larger volume in damage risk, which determines the risk for fatigue. For the manufacturing through Tailored Forming, inducing residual stresses can optimize the use of materials and help saving resources.

In order to verify the presented findings, further bearing fatigue life tests should be conducted. For the hybrid shaft (Fig. 1a), this has already been started and first results show good accordance to the calculation results. Accordingly, adapted manufacturing processes can be developed in order to utilize the mentioned advantages for large-scale applications. This will extend the presented approach and help optimising commonly used machine elements under rolling contact fatigue.

\section{Acknowledgment}

The results presented in this paper were obtained within the Collaborative Research Centre 1153 "Process chain to produce hybrid high performance components by Tailored Forming" in the subproject C3. The authors would like to thank the German Research Foundation (DFG) for the financial and organisational support of this project. 


\section{References}

[1] W. Steinhilper, B. Sauer (Eds.), Konstruktionselemente des Maschinenbaus 2, 7th ed., Springer Vieweg, Berlin Heidelberg, (2012).

[2] T. Coors, F. Pape, G. Poll, Concept for enhancing machine elements by residual stresses and tailored forming, Proceedings of IAMOT 2017, ISBN: 978-3-200-04986-4, (2017) 2040 - 2050.

[3] F. Pape, T. Neubauer, O. Maiß , B. Denkena, G. Poll, Influence of Residual Stresses Introduced by Manufacturing Processes on Bearing Endurance Time. Tribology Letters, 66(205), (2017) 65 - 70. https://doi.org/10.1007/s11249-017-0855-3

[4] A.P. Voskamp, Rolling Contact Fatigue and the Significance of Residual Stresses, Deutsche Gesellschaft für Metallkunde, Proceedings: Residual Stresses in Science and Technology (1987) 713-720.

[5] T.A. Harris, M.A. Ragen, R.F. Spitzer, The Effect of Hoop and Material Residual Stresses on the Fatigue Life of High Speed, Rolling Bearings, Tribology Transactions, 35:1, (1992) 194-198.

[6] T. Neubauer, Betriebs- und Lebensdauerverhalten hartgedrehter und festgewalzter Zylinderrollenlager, Phd. Thesis, Leibniz Universität Hannover, (2016).

[7] Mildebrath, M.; Blohm, T.; Hassel, T.; Stonis, M.; Langner, J.; Maier, H. J.; Behrens, B.-A. Influence of Cross Wedge Rolling on the Coating Quality of Plasma-Transferred Arc Deposition Welded Hybrid Steel Parts, International Journal of Emerging Technology and Advanced Engineering, (2017).

[8] H.J. Fahrenwaldt, V. Schuler (Eds.), Praxiswissen Schweißtechnik. Werkstoffe, Prozesse, Fertigung, Vieweg+Teubner Verlag, Wiesbaden, (2009).

[9] H. Hertz, Über die Berührung fester elastischer Körper. Journal für die reine und angewandte Mathematik, Berlin, (1881) 156-171.

[10] G. Poll, L. Deters, Lagerungen, Gleitlager, Wälzlager. in Konstruktionselemente des Maschinenbaus 2, W. Steinhilper, B. Sauer (eds.), Springer (2008).

[11] F. Pape, O. Maiß, G. Poll, B. Denkena, Reibungsminderung bei Wälzlagern und Gleichlaufgelenken durch eine innovative Hartbearbeitung. In: Sonderband Abschlußkolloquium „Ressourceneffiziente Konstruktionselemente“ SPP 1551, 58. Tribologie-Fach-tagung 2017, Goettingen, (2017) 21 - 37.

[12] E. Ioannides, T.A. Harris, A New Fatigue Life Model for Rolling Bearings. ASME Journal of Tribology, 107(3), (1985) 367-377. https://doi.org/10.1115/1.3261081

[13] E. Ioannides, G. Bergling, A. Gabelli, An analytical formulation for the life of rolling bearings, Acta Polytechnica Scandinavica, Mechanical engineering series No. 137, (1999).

[14] K. Dang Van, B. Griveau, O. Message, On a New Mulitiaxial Fatigue Criterion: Theory and Application. In: Mechanical Engineering Publications, (1989) 479-496.

[15] T. Coors, F. Pape, G. Poll, Enhancing Machine Elements by Residual Stresses, Optimized Surfaces and Tailored Forming. In: Proceedings, 21st International Colloquium Tribology, TAE, Esslingen, (2018) 277-278.

[16] F. Pape, T. Coors, Y. Wang, G. Poll, Fatigue life calculation of load-adapted hybrid angular contact ball bearings, Lecture Notes in Mechanical Engineering, Springer, doi: 10.1007/978-98113-0411-8_36, (2018). https://doi.org/10.1007/978-981-13-0411-8_36 